\title{
Chapter 11 \\ Reframing Health Promotion Research and Practice in Australia and the Pacific: The Value of Arts-Based Practices
}

\author{
Wendy Madsen, Michelle Redman-MacLaren, Vicki Saunders, \\ Cathy O'Mullan, and Jenni Judd
}

\subsection{Introduction}

In health promotion research, the arts can take many forms: as the focus of the research or evaluation; as a tool of inquiry; as an avenue of dissemination; or as a combination of each of these. Each art form occurs within a place-based or social and spatial context, and it is the interdependence of form and context that gives rise to ethical and methodological tensions. In this chapter, we argue that arts-based research $(\mathrm{ABR})$ is an aesthetic, iterative, and organic research process and health promotion practice that brings to the fore ethical and methodological tensions

\footnotetext{
W. Madsen

School of Health, Medical and Applied Sciences CQ University,

Rockhampton North 4702, QLD, Australia

e-mail: w.madsen@cqu.edu.au

M. Redman-MacLaren

College of Medicine and Dentistry James Cook University, Cairns 4870, QLD, Australia

e-mail: michelle.maclaren@jcu.edu.au

V. Saunders

First Peoples Health Unit, Queensland Conservatorium Research Centre, Griffith University,

Gold Coast Campus, Parklands Dr, Southport 4222, QLD, Australia

e-mail: v.saunders@griffith.edu.au

C. O’Mullan

School of Health, Medical and Applied Sciences, CQ University Bundaberg,

Bundaberg 4670, QLD, Australia

e-mail: c.omullan@cqu.edu.au

J. Judd $(\bowtie)$

Centre for Indigenous Health Equity Research, Centre for Emotional Health and Wellbeing,

School of Health Medical and Applied Sciences, Central Queensland University,

Bundaberg 4670, QLD, Australia

e-mail: j.judd@cqu.edu.au
} 
inherent in participatory research. The value of ABR lies in how it advances and enhances scientific practices and methodologies. However, there are also tensions inherent in designing studies that respond to community-led research priorities because ABR provides opportunities for ethical and methodological development/ advancement.

\subsection{Framing and Reframing Arts and Health Promotion Research}

Arts-based research (ABR) emerged from within qualitative research approaches of the 1990s (Capous-Desyllas and Morgaine 2018), although visual and audio data have been used in social anthropology and historical research for many decades (Banks 2007). Whereas anthropological and historical researchers used visual and audio data in association with other data such as documentary evidence or informant interviews, ABR's relationship with data is often more multifaceted and multidirectional. ABR disrupts more traditional understandings of what data are and can be. Data generated in ABR can take the form of visual, auditory, performance, or literary art; the art may pre-exist the research or be created as part of the research process. The art may also be used to generate meaning within the research process or as part of the knowledge translation process (Fraser and al Sayah 2011). Critically, ABR can "extend" what and how we understand by opening alternatives to propositional or conceptual ways of knowing to also include symbolic, expressive, experiential, and practical knowledge (Daykin and Stickley 2016). These primarily aesthetic extensions can disrupt, or challenge, established research traditions.

While the use of qualitative research methods is central to much health promotion research to better understand communities' needs (Salazar et al. 2015; see also Chap. 1, this volume), there are a number of challenges associated with using ABR practices and approaches. These challenges include ontological and epistemological (what is real and how it is known) differences, as well as ethical and methodological issues arising before, during, and after the research. Arts practitioners and researchers usually employ constructivist, critical, or participatory paradigms. In contrast, health promotion researchers and practitioners are not immune to broader narratives around evidence-based practice, and there are pressures to demonstrate effectiveness and use evidence that is not "too" subjective. Thus, it is not surprising that more positivist approaches, such as quantitative or mixed methods research, are increasingly being used to evaluate the impact of ABR approaches, resulting in fundamental differences in opinion as to whether or not it is possible to quantify the "unquantifiable" (Blomkamp 2015).

Related to these epistemological issues are pragmatic issues in how the arts have been co-opted to meet the agendas of other fields of study, such as personal wellbeing (Scott et al. 2018), social and economic development (Ashley 2015), and urban renewal (Pollock and Paddison 2014; Webb 2014). Health promotion researchers and practitioners are at risk of such instrumentalism when working in 
partnership with artists to undertake ABR projects in which the art emphasizes process over product or outcome over process (this can also lead to team antagony; see Chap. 21, this volume). Instrumentalism overlooks the broader aesthetics of the art process (aesthetics of experience) and product (aesthetics of beauty) (Graham 2005; Stroud 2014). Thus, it is helpful for health promotion practitioners and researchers to critically reflect upon their relationships with the artists they work with as well as how they view the role of art in their work. When ABR is undertaken by the researcher who is also the artist, such aesthetic tensions become less relevant.

There is potential for the arts to be used across the five action areas of the Ottawa Charter-develop personal skills, create supportive environments, strengthen community action, reorient health services, and build healthy public policy-to directly address the social determinants of health (World Health Organization 1986; see also Chap. 1, this volume). The four case studies outlined in this chapter focus on strengthening community action, developing personal skills, and creating supportive environments. Written as place-based narratives, each case study explores ethical and/or methodological challenges associated with ABR. Reflecting the strengths of $\mathrm{ABR}$, it is in the telling of a place-based narrative that the learning is revealed.

\subsection{Case Studies}

\subsubsection{Case Study 1: Evaluation of IT ALL BEGINS WITH LOVE}

The first case study outlines a mixed methods evaluation of a theater production. In this case, there was methodological complexity and a few ethical complications. These complications relate to the diverse ways many health promotion practitioners have used the arts to tap into the public's cognitive and emotional understanding of difficult social topics.

IT ALL BEGINS WITH LOVE emerged out of a series of community consultations undertaken in 2012 by Creative Regions, a not-for-profit arts-production company in Bundaberg, Queensland, Australia. Domestic and family violence (DFV) was identified as a significant issue in the community that needed to be talked about to decrease the social stigma associated with it so more women would seek help. Rod Ainsworth, a renowned playwright, worked with local counseling, DFV support agencies, and local media to develop a verbatim theater production to raise social consciousness around the issue. Twelve women who had experienced DFV but who were then safe were interviewed, and excerpts from these transcripts were used to develop the script-a process that took three years as various drafts were distributed between Rod and the counselors.

Wendy Madsen (WM), one of the authors of this chapter, was asked to evaluate the production after it gained funding for a tour of Queensland in 2015. As a qualitative health promotion researcher committed to participatory research, WM could not countenance undertaking a pre-post survey of a stage production around such an 
emotional topic. Wendy also recognized the range of confounding factors that could influence any evaluation, such as: the venue was different for every performance, meaning the actors would need to adapt to each venue; the actors were professional, but their energy levels would vary between performances; the audience may or may not have insights into theater techniques of communication; and the relationship between the audience and their theater could condition them to expect entertainment, when this production was meant to challenge rather than entertain. Trying to undertake in-depth interviews was unrealistic, as the production was frequently moving. Wendy needed to find a participatory approach that provided depth as well as breadth around the following issues: (1) Could a socially engaged theater production raise social consciousness around such a sensitive topic? (2) What were some of the challenges of undertaking and touring such a production?

Luckily, Rod was not only the playwright but also the producer and was committed to working in a participatory manner. We formed a small group consisting of Rod, a representative from one of the counseling agencies who provided on-site counseling support, a representative from the funding body, one of the actors, and WM. Together we worked through the issues of how to evaluate this production in a way that was sensitive to the topic and context, but also practical. We decided to draw data from a range of sources. We offered audience members two online surveys (one was available immediately after each performance, and one was open for a month after the last performance to allow audience members to reflect on the production). Next, we provided audience members with paper and pens and allowed five minutes between the end of the performance and the beginning of the Question and Answer session for them to write down thoughts and questions (these pieces of paper were collected at the end of each event). Finally, we utilized ethnographic data consisting of in-depth interviews with various stakeholders, as well as field notes. Wendy was responsible for the analysis and write-up of the project and so was consistently in touch with the other members of the research team, seeking out their views and interpretations of these data.

This was WM's first time working with professional artists to evaluate an artsbased production that had health promotion implications. WM admits she was on a huge learning curve as she tried to understand issues of evaluation within the arts sector and how these issues related to health promotion. There have been many claims over the years that the arts contribute to the health and social wellbeing of communities; however, these claims have been frequently questioned by insufficient evidence. While not "gold standard," we were nevertheless able to demonstrate that this production contributed to raising the consciousness around DFV for many who saw the performance. The results suggested that many in the audience felt increased empathy for those caught in DFV situations, and some audience members reflected on the quality of their own relationships. We concluded that when undertaken as part of a broader shift in social conversations, the arts can and do play a significant role in tapping into the public's cognitive and emotional understanding of these difficult social topics (see Madsen 2018 for more on this project). 


\subsubsection{Case Study 2: IMPACT Community Choir}

The second case study shifts the focus from evaluation of the arts to using the arts to generate data with members of the disability community - a group generally seen as difficult to research. Compared to the first case study, additional ethical complexities impacted the methodology of this second case. As such, this next case demonstrates how arts-based methods were used as a tool to elicit understanding and generate knowledge and well-being.

Once a week the halls of IMPACT, a community service organization in Bundaberg, are filled with the sweet sounds of the IMPACT Community Choir. The choir was established in 2011 for people with a disability and includes people with profound and multiple disabilities; it has also expanded to include community members from a diverse range of local community organizations who are experiencing mental health issues. There are now over 60 members. Volunteers support the choir, as do paid carers (i.e., caregivers) and support staff who assist with the musical accompaniment. Performances are in high demand, and the choir regularly travels throughout the region in the widely acclaimed "rock-bus." It is now well known that choir singing is associated with a range of health benefits; participating in a choir also provides the opportunity for members to access additional social support and may provide a new social identity (Hassan 2017). For people living with a disability or a mental health condition, being part of a choir presents an opportunity for meaningful activity and social connectedness. As part of an ongoing research partnership with IMPACT, we (Cathy O'Mullan and Jenni Judd, two of this chapter's authors) were asked to develop a creative way to showcase the impact of the choir for the participants - in particular, how participating in the choir contributes to improving their health and well-being.

Historically, people with a disability are an underrepresented group in research and in the evaluation of programs and services, and this is particularly true for people who have profound and multiple disabilities. Although we were keen to hear the perspectives of those in the IMPACT choir, we were also conscious that many members had limited cognitive abilities and would not be able to participate in more traditional research approaches such as focus groups or interviews. As such, if we used these methods, only the most able (a small number) would be able to participate, which presented us with a dilemma since we wanted to ensure that we could hear all choir members' points of view. We needed to find a participatory research approach that was inclusive and allowed individuals the autonomy of making their own decisions without further marginalizing people with a disability. Fortunately, IMPACT is committed to working in a participatory manner and was open to forming a working group to oversee the project. The group consisted of us (Cathy and Jenni), a paid support worker, and case managers with experience in working with these choir members. As part of this group, we brainstormed moral and ethical issues relating to the project and practical ideas for moving forward.

We chose to use photovoice-an arts-based method using photographs to provide insight into participant experiences - to engage and provide a "visual voice" to 
all choir members who chose to participate. Photovoice is a participatory action research methodology that uses photography as a tool to access other people's worlds (Wang and Burris 1997). By taking photographs, individuals are able to explore their experience of daily life and promote critical dialogue with respect to important community issues. While the methodology can be used flexibly (Seed 2016), individuals are typically encouraged to select a number of photographs for discussion either in a group setting or on a one-to-one basis. Over the past two decades, photovoice has been effectively used as a participatory research approach for engaging with marginalized and vulnerable populations (Dassah et al. 2017) and offers an empowering and creative tool to help gather rich, qualitative data. Participatory research methods such as photovoice have provided a much-needed research approach to capture the voices of those with a physical or intellectual disability. Indeed, a number of projects have used photovoice as an avenue for people with a disability to communicate their health priorities and actively contribute to health promotion planning and service delivery (Dassah et al. 2017). Although there is a dearth of literature involving those with profound and multiple learning disabilities, Cluley (2017, p. 42) argues that photovoice can be used flexibly to provide such individuals with an opportunity to "voice their words visually," thereby opening up this approach to include people of all cognitive abilities.

Based on discussions with the working group and through our communication with choir members, it was apparent that photovoice's "gold standard" approach, which typically includes interviews and focus groups to help analyze the photographs, was not going to work. To facilitate inclusion, we needed to be realistic and mindful about the contribution expected from choir members. Hence, photovoice was used flexibly and adapted to suit this project. While speaking for people with a disability is widely frowned upon, we included support workers across all stages of the project to facilitate the inclusion of members' voices. Each support worker, for example, partnered with a choir member to help them to identify photo opportunities and select appropriate photos. In partnership, they worked together to interpret the meaning of each photograph and to develop a caption. We then analyzed the photos and captions based on conversations with each choir member (when appropriate) and their support worker.

Our findings reveal how participation in the choir has made a positive impact on choir members' self-esteem, their sense of calm and well-being, and their growth as individuals. Furthermore, participation has also fostered a sense of belonging and social connectedness among members. At a community level, those who have been involved as volunteers, researchers, and as part of an audience have reported feeling elevated and deeply moved by the experience. Of note, the findings have also resulted in the publication of a community photo book (see Fig. 11.1), which is being used to raise awareness of the benefits of this type of program.

Although we had used photovoice before, we had never used this approach with people who have a disability. What we have learned is that we can include individuals with profound and multiple disabilities in participatory and emancipatory research projects. The IMPACT choir performances demonstrate the power of singing to bring people and communities together, to promote social inclusion, and 
Fig. 11.1 Example of a photovoice photograph titled "Growth: The choir helps me learn and grow". (Reproduced with permission from the authors. Copyright $(\odot 2021$ Wendy Madsen, Michelle Redman-MacLaren, Vicki Saunders, Cathy O'Mullan, and Jenni Judd. All rights reserved)

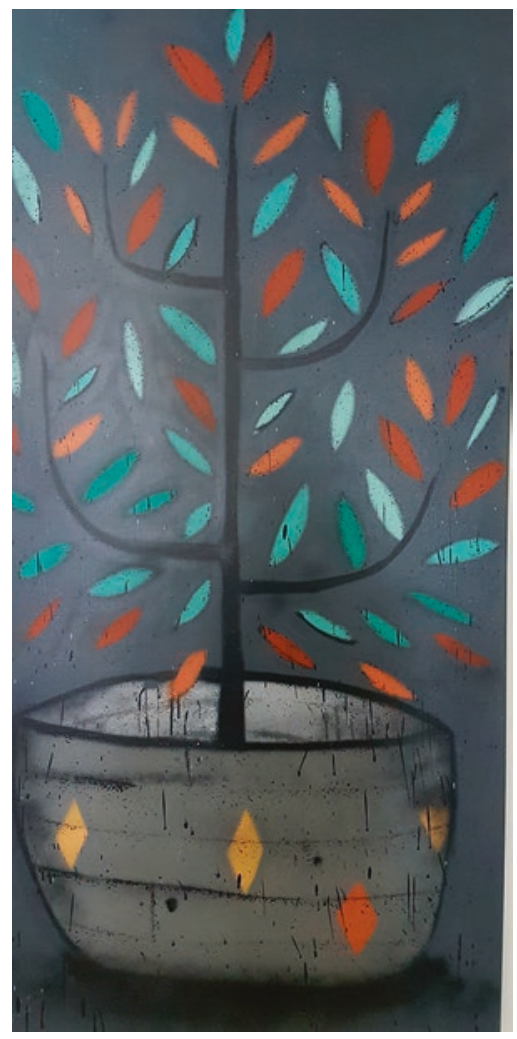

importantly to provide a collective voice for people with a disability and/or a mental health condition. This case study shows that ABR can provide a highly inclusive approach to research, allowing those who have traditionally been excluded from the data-generation process to be active participants.

\subsubsection{Case Study 3: Implications of Male Circumcision for Women in Papua New Guinea, Including for HIV Prevention}

The third case study again uses an arts-based method to generate data and to make meaning from the data, and takes into account some ethical and methodological challenges associated with researching cross-cultures, gender, language, and varied literacy levels.

For many women in Papua New Guinea (PNG), HIV is an ever-present risk. PNG is a hyper-diverse Pacific island nation experiencing a concentrated human immunodeficiency virus (HIV) epidemic that is largely heterosexually transmitted. 
Addressing HIV in PNG is a challenge. The seven million people of PNG speak over 830 languages. The rural majority (85\%) live a predominantly subsistence lifestyle, with limited educational opportunities for girls and women; approximately $50 \%$ of women in PNG are illiterate. Given that male circumcision reduces the risk of female-to-male HIV transmission and thus reduces HIV at a population level, it is currently being explored as an HIV-prevention option in PNG. Exploring the implications of male circumcision with women is essential to inform balanced, evidence-based health policy that will result in positive, intended consequences.

In 2013-2014, I (Michelle Redman-MacLaren, one of this chapter's authors) and Rachael Tommbe, a health researcher from Enga Province in PNG, worked with over 60 rural and urban women in seven interpretive focus groups at two sites to explore implications of male circumcision for the women as wives, partners, and/or mothers (Redman-MacLaren et al. 2017). Qualitative research methods often rely on individual or group interviews to co-generate stories that help the researcher/s understand the phenomenon being studied. These methods are consistent with the way information is shared in PNG, where knowledge, art, and lore are often transmitted orally. However, the highly accepted oral way of communicating in PNG is to rely upon a big man or big meri (literally, important man or important woman) to be a spokesperson for the group. In this study, we needed to understand the implications of male circumcision for all women, not just for the spokeswomen/leaders. Thus, we used ABR to enhance participation and inclusivity in the research process. During the interpretive focus groups, whole-of-group discussions were initially held with women to contextualize the research. Women then worked in smaller story circles to discuss "chunks" of existing data from a previous male circumcision study. A final process involved storyboarding.

Storyboarding is a technique used in the visual arts and has recently been adapted for use in community development and participatory research (Pittaway and Bartolomei 2012). In this study, storyboarding was used to elicit different understandings about male circumcision from a wide range of rural and urban women. Women self-organized into story circles of four to five participants, discussed the prompt questions, and drew their responses. The following were the four prompt questions used to elicit information: (1) What is happening (how, who, where, when)? (2) What is the outcome for men? (3) What is the outcome for women? (4) What needs to happen next? (See Fig. 11.2 for an example process of storyboarding.)

Women drew pictures on large sheets of paper using crayons, felt pens, highlighter pens, and pencils (Fig. 11.3). Various-sized drawings emerged, and women organized information and drawings differently. Some women drew only pictures, while others drew a combination of pictures and words (Fig. 11.4). Some women started drawing immediately; other story circles took more time to discuss the questions first and then draw considered responses. Although a spokeswoman from each story circle shared an explanation of the drawings with the whole group, the drawings often led to extended discussions with a wide range of women participating.

The visual method of storyboarding was well received by the women we worked with in PNG. Storyboarding stimulated succinct, targeted representations of 
Storyboarding to understand implications of male circumcision for women

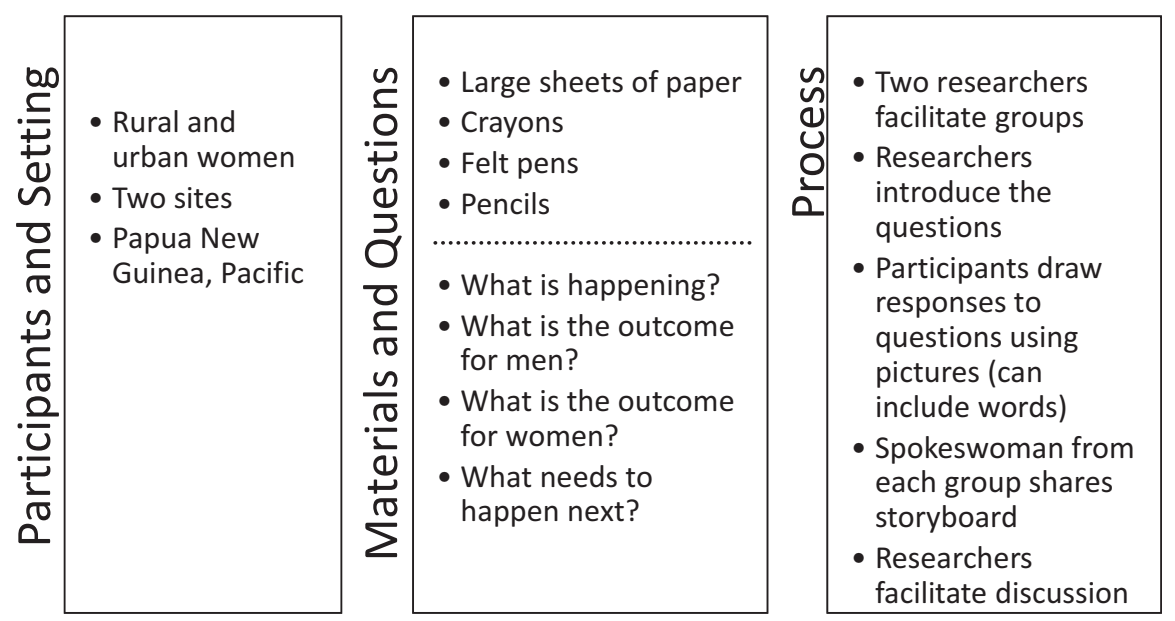

Fig. 11.2 Storyboarding to understand implications of male circumcision for women. (Reproduced with permission from the authors. Copyright () 2021 Wendy Madsen, Michelle Redman-MacLaren, Vicki Saunders, Cathy O'Mullan, and Jenni Judd. All rights reserved)

women's knowledge and experience of male circumcision, and it offered a different way of communicating about sensitive sexual health issues that encouraged high levels of participation in the research process. The kinesthetic experience of drawing appeared to elicit different types of information to that shared in interviews and focus groups. The storyboard artifacts were used to provide more detailed reporting of research findings in a way that transcended language and cultural barriers. The findings recorded have informed health promotion activities with men and women, guided advocacy with policy makers, and furthered other research projects.

In this case study, ABR provided an ethical means of including a diverse range of participants in the research process.

\subsubsection{Case Study 4: Using Poetic Inquiry to Story Aboriginal Recovery in Mental Health Care}

In the fourth and final case study, we describe ABR as a way of ethically and methodologically engaging with stories of well-being and recovery of Indigenous Australians experiencing mental health issues. However, this final case challenges us to consider our positionality as health promotion researchers.

In the texts that inscribe Indigenous peoples in mental health care statistics, stories of recovery or living life well with a diagnosis of mental illness are not usually included. In the reports that inscribe stories of well-being and recovery in mental health care service delivery, indicators to describe Indigenous peoples are not often 


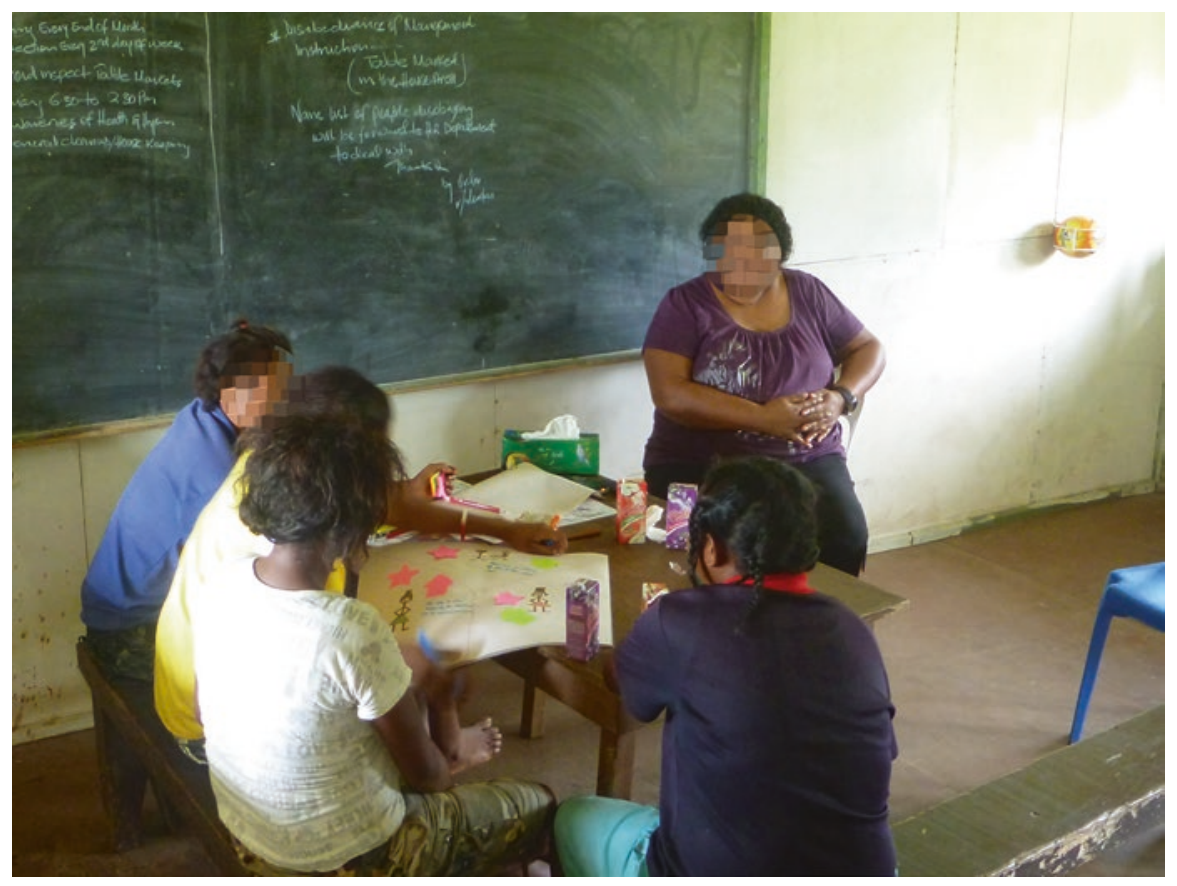

Fig. 11.3 Young women draw their storyboards, supported by Rachael Tommbe. (Reproduced with permission from the authors. Copyright ( $\odot 2021$ Wendy Madsen, Michelle Redman-MacLaren, Vicki Saunders, Cathy O’Mullan, and Jenni Judd. All rights reserved)

recovery-oriented. This research project began with the search for indicators of recovery among stories of Indigenous people living with a diagnosis of mental illness in Far North Queensland. To amplify Indigenous voice and modes of storytelling, and to engage with the silences and the ethical and moral imperatives that asking Indigenous questions about statistics and stories of Indigenous recovery foregrounded, the research methodology evolved into poetic inquiry.

Poetic inquiry is the transformation of ideas or words from research into poetry (Butler-Kisber and Stewart 2009). According to Monica Prendergast (2009), poetic inquiry as a process of seeing, caring, and understanding is all about voice, and there are three main types of voice used in poetic practices and methods of research: vox theoria, vox participare, and vox autoethnographia. Poetic inquiry can be performed using found poetry, where the actual words of participants are used (vox participare); or it can be performed using generated poetry, where researchers poetically reflect on their own subjectivities/responses in the work (vox autoethnographia); or it can be written from, or in response to, works of literature/theory in a discipline or field or poems written about poetry and/or inquiry itself (vox theoria) (Prendergast 2009). The results can be shared publicly or kept as a private interpretive tool (Butler-Kisber 2017) in which poems are approached as a source of data, a form of data, a way of representing complex or ineffable social dilemmas, or a 

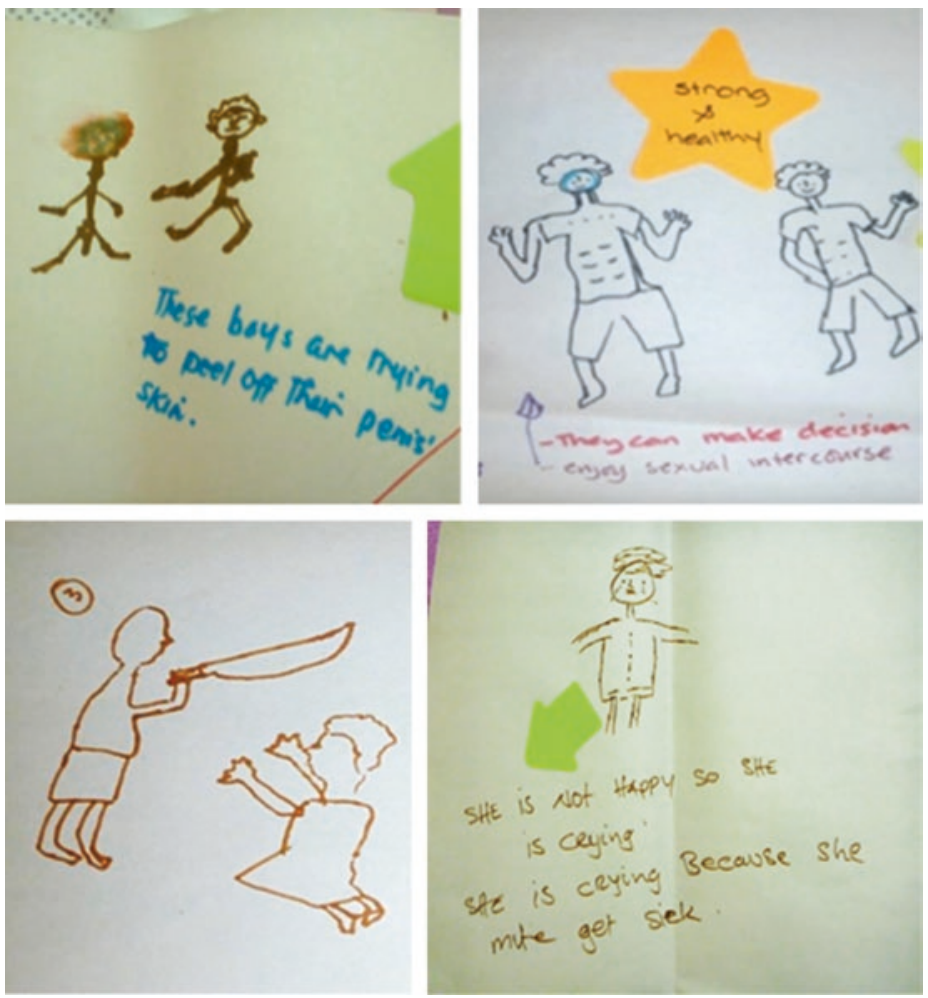

Fig. 11.4 Responses to questions considered by women in the story circles. (Reproduced with permission from the authors. Copyright (C) 2021 Wendy Madsen, Michelle Redman-MacLaren, Vicki Saunders, Cathy O’Mullan, and Jenni Judd. All rights reserved)

methodology or means through which to link research processes to research outcomes for transparent, powerful effect (Van Luyn et al. 2016). Poetics can be viewed as a discourse articulating "the relationship between the creative work and its critical inputs and outcomes" (Lyall 2014, p. 134, citing the work of Lasky 2013).

Indigenous poetics necessarily includes another dimension of representation or expression - it includes a way of listening that is active and deep and centers around a particular sense of place, belonging, and country. Miriam Rose has called this dimension of Indigenous listening “Dadirri” see Miriam Rose Foundation https:// www.miriamrosefoundation.org.au/) — a way of listening that does not just involve the ears; that is not necessarily about sound; and that is sometimes about listening to the absence of sound, the absence of a story where there once was one, or where there perhaps should be one. It is also about storywork, or the work of stories. It is about the way stories embed multiple layers of meanings that interweave cultural signifiers as reference points between the reader/listener and the storyteller (Archibald 2008a, b; Bessarab and Ng'andu 2010; Kovach 2010). 
A Gunggari woman and an Aboriginal researcher, Vicki Saunders, one of the authors of this chapter, works with and within what Sousain Abadian (2006) has called "culturally toxic stories." This term describes the way settler or colonizing stories do harm to Indigenous storytelling practices, cultural and community stories in an ongoing way. A key quote from one of the storytellers and co-researchers that shaped the direction for this research project captures it well:

It's about the way they tell their stories about us. It's about the way we then have to tell our stories within their stories. No wonder you go womba (mad/crazy) (Saunders 2016, p.16).

All research at its core is about questioning, and it is the form and type of research question that drives methodological choice. The questions asked of VS as an Aboriginal researcher and woman required a more holistic methodological response and deliberation (and unlearning). The poem that concludes this section captures in poetic form some of the critical deliberations and findings of answering these questions. (See Fig. 11.5 for an example process of poetic inquiry).

As an Aboriginal researcher embedded within a place-based web of ancestral and social relationships that locate her identity and citizenship status, Vicki cannot not be a participant in the storytelling; that is, she is not quite nor can she be objective in this context. Underpinning her research standpoint is a foundational assumption that to do so could create harm and could also harm the precious stories that Indigenous peoples hold and share. Using poetic license, Vicki listened deeply for the absence of stories of recovery in contexts of Aboriginal mental health care. She listened to the way these absences revealed themselves through people's stories through the poetic - through verse rather than prose - disrupting the way the stories

Using poetic inquiry to story Aboriginal recovery in mental health care
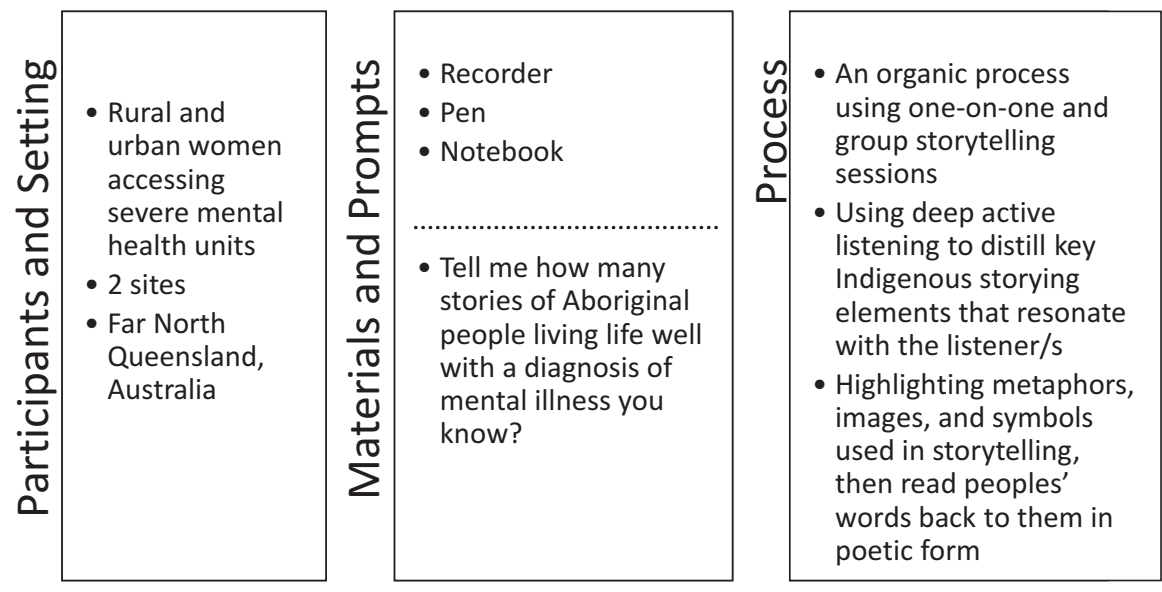

Fig. 11.5 Using poetic inquiry to story Aboriginal recovery in mental health care. (Reproduced with permission from the authors. Copyright $\odot 2021$ Wendy Madsen, Michelle Redman-MacLaren, Vicki Saunders, Cathy O’Mullan, and Jenni Judd. All rights reserved) 
of Aboriginal people in mental health care are usually told in ways that others now describe as deficit discourses.

\section{Re-covering methodologically}

There are many ways to ask a question

And many questions to ask

The trick to seeking answers

Is knowing which answer you want at the start

But questions have a habit

An irritating trend

An inevitable growing spiral

With no beginning and no end

The what of questions asked

Comes from the questions why

And to have the question answered

depends on who it is asked by.

How answers are found

Is all about where and when

And from the answers, you already know

Ultimately is where "new knowledge" is located

in the end.

But knowing and knowledge is a funny thing

In the world of Indigenous science

Especially in the field of research about those

named Aboriginal or Indigenous mental health clients

In the "mental health" arena-

to be Indigenous is mainly deemed a curse

In the discourses of "health,"

it seems nothing is counted nor countered worse.

Indigenous questions are all about Who

And how our stories are related

And answering unasked questions

About how knowledge is used and how "truths" are created

Being human

is to story that which we deem "real."

About the truths that we know

and can't separate from those which we feel.

Where whose reality? is the central question

In the field defining the "real" that gets heard

To ask Indigenous questions

makes an attempt to find "a 'real' answer" faintly absurd

To be able to ask

My first questions come from the heart

Do I have the courage?

How will my words be used?

And how do you express in words of science

Questions better asked of spirit and through art? 
At mental health's so-called cultural interface

Where "knowledge" and "truth" are impossibly blurred

Only questions bound in the "logic of care,"

Cognitocentrism and pathology tend to emerge.

At heart the Indigenous quest is critical

It's challenge-a way of seeing

how knowing relates to doing

and what this means for being

a human researched being.

\subsection{Discussion}

While each of the four case studies used different ABR methods, collectively the case studies raise methodological and ethical issues for health promotion practitioners and researchers, including matters of differing aspirations, expectations, agendas, and power. However, there is a commonality that underpins all of these issues. At the heart of all four case studies was a commitment to relational epistemology within a participatory paradigm. Each case foregrounds or focuses on knowledge drawn from building relationships and dialogue between researchers, community organizations, and participants. In the case of IT ALL BEGINS WITH LOVE, there was a core group of co-researchers comprising artists, a counselor, and a university researcher who shared the decision making. In the IMPACT case, the university researchers partnered with support workers and case managers to work through the ethical issues that arose. The storyboarding case highlighted the need for the researchers to work in a culturally appropriate way in partnership with communities. The poetic inquiry case demonstrated how a researcher embedded within complex social and cultural relationships responded to the ethical and moral demands of working with Indigenous stories in cross-cultural and cross-disciplinary research. Not all ABR projects are located within a participatory paradigm. However, given health promotion's focus on social justice, social activism, and creating social change, it is not unusual that there is a propensity toward participatory ABR. As Foster (2012) suggests, arts activism can offer a platform for marginalized groups and help facilitate a different way of thinking to challenge oppression.

However, there are several implications for health promotion when relationality is privileged in ABR. First, considerable time is required to build relationships of trust that reflect genuine collaboration and shared decision-making (for further theoretical discussion of collaborative functioning in health promotion research, see Chap. 21, this volume). As highlighted in our case studies, when using ABR, health promotion researchers and practitioners may need to spend time understanding the variety of perspectives and language. Likewise, when working in a cross-cultural context, especially one in which roles and relationships are viewed from differing perspectives, considerable effort is needed to learn what is culturally appropriate. 
Consequently, universities, partner organizations, or funding bodies may query the amount of time spent on participatory ABR projects, particularly regarding "returning benefits"- that is, the outcomes or outputs gained in comparison to the time and effort invested. There are challenges in evidencing relational outcomes or outcomes of the time spent building shared understandings with research partners and coresearchers. These outcomes are often intangible and only become visible over time; addressing these challenges means putting a priority on quality and social and relational dimensions of research results rather than quantity. The importance of a cultural guide/mentor advisor in projects with cultural diversity is a key element for research with other cultural groups. In research focused on contributing to grassroots social change (see Capous-Desyllas and Morgaine 2018 for multiple examples), changes can be quite slow, with evidence of change often emerging outside the usual timeframes allowed for in research data collection. For example, each of the projects required a significant time investment at the beginning of the project; the IT ALL BEGINS WITH LOVE project involved three years of community consultation, with the evaluation component introduced at the end of that process.

The second implication is that of determining whose agenda or voice is being heard. Participatory ABR projects enable a range of people to be involved, many of whom have been excluded from participating in the research process in the past (although they have often been the objects of research). We (Cathy and Jenni) in the IMPACT project needed to adopt a flexible approach to be able to capture the voices of people with cognitive and physical disabilities. As Tina Cook and Pamela Inglis (2012) note, gaining the perspectives of those with disabilities can enable new understandings if we take a participatory, collaborative, and recursive approach. Adapting the photovoice methodology to suit the participants, and omitting customary interviews to explore the ideas further, allowed their stories to be told. The storyboarding and poetic inquiry cases both demonstrated how ABR enabled the inclusion of voices not always heard. Indeed, those who continue to live under the oppression of colonization are conscious that their stories may be filtered through the lenses of the colonizers (Smith 2012). In the poetic inquiry case study, ABR allowed Indigenous stories to be told directly by Indigenous voices.

Thus, the third implication is that of power and participation. Traditional research practices privilege those with numeracy, literacy skills, and knowledge, in both researchers and those who form the focus of research. People who come from oral knowledge traditions or whose cognitive processes act as barriers to participation in research projects are at a disadvantage in what is researched, how it is investigated, and what happens with data when they are collected. Participatory ABR helps to reduce power differences using genuine decision-sharing processes, inclusive data generation processes, collaborative analysis, and dissemination (Capous-Desyllas and Morgaine 2018; Ledwith and Springett 2010). Building and maintaining relationships of trust as well as a commitment to redressing power imbalances are critical for more effective health promotion research (Madsen and O'Mullan 2018). 


\subsection{Conclusion}

While ABR practices are inherently aesthetic in that they emphasize arts processes and art products, the specific outcomes illustrated in these case studies demonstrate that $\mathrm{ABR}$ can also address issues of power and trust and amplify local knowledge and voices. Thus, there is a strong resonance between ABR practices and the values and actions within the Ottawa Charter (World Health Organization 1986) that provide a strong foundation for this work. ABR practices can enable different understandings of health promotion, well-being, and research, and can help reshape the traditional role of researcher from objective observer to co-participant/co-facilitator/ co-researcher. While the outcomes from each of the case studies were unique, central to the success of all of them were the iterative, organic research processes and practices that responded to priorities of communities. Dedicating the necessary time to building trust and partnerships is what enabled these projects to succeed, and ABR was a critical part of this process. The ABR practices used in these case studies reinforced group potential and local knowledge, often within challenging social environments in which participants had little control over external or internal factors.

For the authors of this chapter, the value of using ABR practices in health promotion research lies in how it aligns with and reframes our positions as health promotion practitioner-researchers. ABR processes are juxtaposed with traditional research processes, including assumptions underpinning reasoning, validity, data construction, and interpretation. Importantly, ABR uses aesthetics to bridge the gap between researchers and the communities in which they work by generating new knowledge that is not only valid and useful, but also beautiful and aesthetically and emotionally rich.

\section{References}

Abadian, S. (2006). Cultural healing: When cultural renewal is reparative and when it is toxic. Pimatisiwin: A Journal of Aboriginal and Indigenous Community Health, 4(2), 5-28.

Archibald, J. A. (2008a). Indigenous storywork: Educating the heart, mind, body, and spirit. Vancouver: UBC Press.

Archibald, J. A. (2008b). An Indigenous storywork methodology. In Handbook of the arts in qualitative research: Perspectives, methodologies, examples, and issues. Thousand Oaks: Sage Publications.

Ashley, A. J. (2015). Beyond the aesthetic: The historical pursuit of local arts economic development. Journal of Planning History, 14(1), 38-61.

Banks, M. (2007). The Sage qualitative research kit, 8 vols: Using visual data in qualitative research. London: Sage.

Bessarab, D., \& Ng'andu, B. (2010). Yarning about yarning as a legitimate method in indigenous research. International Journal of Critical Indigenous Studies, 3(1), 37-50.

Blomkamp, E. (2015). A critical history of cultural indicators. In Making culture count (pp. 11-26). London: Palgrave Macmillan. 
Butler-Kisber, L. (2017). Lynn Butler-Kisber defines poetic inquiry [streaming video]. SAGE research methods. Retrieved from http://methods.sagepub.com/video/lynn-butler-kisberdefines-poetic-inquiry. Accessed 16 Nov 2018.

Butler-Kisber, L., \& Stewart, M. (2009). The use of poetry clusters in poetic inquiry. In M. Prendergast, C. Leggo, \& P. Sameshima (Eds.), Poetic inquiry: Vibrant voices in the social sciences (pp. 3-12). Rotterdam: Sense Publishers.

Capous-Desyllas, M., \& Morgaine, K. (2018). Preface. In M. Capous-Desyllas \& K. Morgaine (Eds.), Creating social change through creativity: anti-oppressive arts-based research methodologies (pp. vii-xix). Cham: Palgrave Macmillan.

Cluley, V. (2017). Using photovoice to include people with profound and multiple learning disabilities in inclusive research. British Journal of Learning Disabilities, 45(1), 39-46.

Cook, T., \& Inglis, P. (2012). Participatory research with men with learning disability: Informed consent. Tizard Learning Disability Review, 17(2), 92-101.

Dassah, E., Aldersey, H. M., \& Norman, K. E. (2017). Photovoice and persons with physical disabilities: A scoping review of the literature. Qualitative Health Research, 27(9), 1412-1422.

Daykin, N., \& Stickley, T. (2016). The role of qualitative research in arts and health. In S. Clift \& P. M. Camic (Eds.), Oxford textbook of creative arts, health, and wellbeing: International perspectives on practice, policy and research (pp. 73-81). Oxford: Oxford University Press.

Foster, V. (2012). What if? The use of poetry to promote social justice. The International Journal of Social Work Education, 31(6), 742-755.

Fraser, K. D., \& al Sayah, F. (2011). Arts-based methods in health research: A systematic review of the literature. Arts \& Health, 3(2), 110-145.

Graham, G. (2005). Philosophy of the arts: An introduction to aesthetics (3rd ed.). London: Routledge.

Hassan, N. (2017). Re-voicing: Community choir participation as a medium for identity formation amongst people with learning disabilities. International Journal of Community Music, 10(2), 207-225.

Kovach, M. (2010). Indigenous methodologies: Characteristics, conversations, and contexts. Toronto: University of Toronto Press.

Ledwith, M., \& Springett, J. (2010). Participatory practice: Community-based action for transformative change. Bristol: Policy Press.

Lyall, M. (2014). Method emerging: A statement of poetics for a project-based PhD. Qualitative Research Journal, 14(2), 134-149.

Madsen, W. (2018). Raising social consciousness through verbatim theatre: A realist evaluation. Arts \& Health, 10(2), 181-194.

Madsen, W., \& O’Mullan, C. (2018). Power, participation and partnerships: Reflections on the cocreation of knowledge. Reflective Practice, 19(1), 26-34.

Pittaway, E., \& Bartolomei, L. (2012). Community consultations using reciprocal research methodologies. Sydney: Centre for Refugee Research, University of New South Wales.

Pollock, V. L., \& Paddison, R. (2014). On place-making, participation and public art: The Gorbals, Glasgow. Journal of Urbanism: International Research on Placemaking and Urban Sustainability, 7(1), 85-105.

Prendergast, M. (2009). "Poem is what?" Poetic inquiry in qualitative social science research. International Review of Qualitative Research, 1(4), 541-568.

Redman-MacLaren, M., Mills, J., Tommbe, R., MacLaren, D., Speare, R., \& McBride, W. J. H. (2017). Implications of male circumcision for women in Papua New Guinea: A transformational grounded theory study. BMC Women's Health, 17(53), 1-10.

Salazar, L. F., Crosby, R. A., \& DiClemente, R. J. (2015). Research methods in health promotion. San Francisco: John Wiley \& Sons.

Saunders, V. -L. (2016). “...”: Using a non-bracketed narrative to story recovery in aboriginal mental health care. PhD thesis: James Cook University.

Scott, K., Rowe, F., \& Pollock, V. (2018). Creating the good life? A wellbeing perspective on cultural value in rural development. Journal of Rural Studies, 59, 173-182. 
Seed, N. (2016). Photovoice: A participatory approach to disability service evaluation. Evaluation Journal of Australasia, 16(2), 29-35.

Smith, L. T. (2012). Decolonizing methodologies: Research and indigenous peoples. London: Zed Books.

Stroud, S. R. (2014). The art of experience: Dewey on the aesthetic. In Practicing pragmatist aesthetics: Critical perspectives on literature and the arts. Amsterdam: Rodopi.

Van Luyn, A., Gair, S., \& Saunders, V. (2016). 'Transcending the limits of logic': Poetic inquiry as a qualitative research method for working with vulnerable communities. In Sharing qualitative research (pp. 95-111). London: Routledge.

Wang, C., \& Burris, M. A. (1997). Photovoice: Concept, methodology, and use for participatory needs assessment. Health Education \& Behavior, 24(3), 369-387.

Webb, D. (2014). Placemaking and social equity: Expanding the framework of creative placemaking. Artivate: a Journal of Entrepreneurship in the Arts, 3(1), 35-48.

World Health Organization. (1986, November 17-21). The Ottawa charter for health promotion: An international conference on health promotion: The move towards a new public health. Ottawa.

Open Access This chapter is licensed under the terms of the Creative Commons AttributionNonCommercial-NoDerivatives 4.0 International License (http://creativecommons.org/licenses/ by-nc-nd/4.0/), which permits any noncommercial use, sharing, distribution and reproduction in any medium or format, as long as you give appropriate credit to the original author(s) and the source, provide a link to the Creative Commons license and indicate if you modified the licensed material. You do not have permission under this license to share adapted material derived from this chapter or parts of it.

The images or other third party material in this chapter are included in the chapter's Creative Commons license, unless indicated otherwise in a credit line to the material. If material is not included in the chapter's Creative Commons license and your intended use is not permitted by statutory regulation or exceeds the permitted use, you will need to obtain permission directly from the copyright holder.

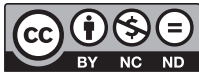

